\title{
EFEITO DO CONDICIONAMENTO OSMÓTICO EM SEMENTES DE Brachiaria brizantha cv. Marandu
}

\author{
Effect of osmoconditioning in seeds of Brachiaria brizantha cv. Marandu
}

\author{
Lisandro Tomas da Silva Bonome ${ }^{1}$, Renato Mendes Guimarães², João Almir Oliveira² \\ Vinicius de Carvalho Andrade ${ }^{3}$, Paula de Souza Cabral ${ }^{4}$
}

\begin{abstract}
RESUMO
A implantação rápida e segura de pastagens por meio de sementes de boa qualidade é condição básica para o sucesso de sua exploração. Com objetivo de contribuir para solução de problemas inerentes às sementes de Brachiaria brizantha, como baixo vigor e desuniformidade de germinação, foi conduzido um experimento, no qual se procurou avaliar o efeito do condicionamento fisiológico nestas sementes. O ensaio, realizado no Laboratório de Análise de Sementes do Departamento de Agricultura da Universidade Federal de Lavras, foi conduzido com diferentes solutos (PEG 6000, $\mathrm{KNO}_{3}$ e PEG $6000+\mathrm{KNO}_{3}$ ), potenciais hídricos (-0,9; -1,1 e -1,4MPa), períodos de condicionamento (12, 24, 48 e 72 horas) e duas testemunhas (presença e ausência de escarificação), sem condicionamento osmótico. Os efeitos dos tratamentos foram avaliados pelos testes de germinação, índice de velocidade de protrusão radicular e tempo para ocorrência de $50 \%$ de germinação. Foi possível concluir que o condicionamento fisiológico promove maior vigor quando as sementes são imersas em solução por um período de 12 horas a potenciais hídricos mais negativos.
\end{abstract}

Termos para indexação: Polietileno glicol, nitrato de potássio, condicionamento fisiológico.

\begin{abstract}
The fast and safe establishment of pastures by means of high quality seeds is a basic condition to the success of its production. With the purpose of contributing towards the solution of problems inherent to the seeds of Brachiaria brizantha, such as poor vigor and non-uniformity of germination, an experiment was conducted to evaluate the effect of the physiological conditioning on the quality of these seeds. The trial, accomplished in the Seed Analysis Laboratory of the Department of Agriculture of the Federal University of Lavras, was conducted with different solutes (PEG 6000, $\mathrm{KNO}_{3}$ and PEG $6000+\mathrm{KNO}_{3}$ ), water potentials (-0.9; -1.1 and $-1.4 \mathrm{MPa})$, conditioning periods $(12,24,48$ and 72 hours) and two checks (with and without scarification, with no osmoconditioning). The effects of the treatments were evaluated by germination tests, root protrusion velocity index and time to occurrence of $50 \%$ of germination. It was possible to conclude that the physiological conditioning promotes greater vigor when the seeds are immersed in solution for a 12 hour period, at more negative water potentials.
\end{abstract}

Index terms: Glycol polyethylene, potassium nitrate, conditioning.

(Recebido para publicação em 26 de janeiro de 2004 e aprovado em 10 de agosto de 2005)

\section{INTRODUÇÃO}

As gramíneas do gênero Brachiaria constituem atualmente, no Brasil, as principais espécies forrageiras tropicais cultivadas. $\mathrm{O}$ interesse dos pecuaristas por essas espécies deve-se à capacidade de produção de matéria seca, aos reduzidos problemas fitossanitários, à estabilidade de crescimento em todas as estações do ano e à ampla adaptabilidade edáfica (CASTRO et al., 1996).

Nas formações das pastagens melhoradas, a Brachiaria brizantha é a principal espécie do gênero no País, porém, a maioria das espécies de gramíneas forrageiras tropicais possui fatores que dificultam a obtenção de altas produções de sementes de boa qualidade, tais como a desuniformidade na emissão das inflorescências, o florescimento irregular dentro das panículas, o baixo número de sementes férteis, a elevada degrana natural e a dormência das sementes, fenômeno fisiológico que dificulta o estabelecimento uniforme das populações e favorece o surgimento de plantas invasoras na pastagem.

Neste sentido, um tratamento a ser experimentado para melhorar o desempenho das sementes de Brachiaria é o condicionamento fisiológico. Esta técnica consiste no controle da velocidade de embebição de água pelas sementes, pelo uso de soluções osmóticas ajustadas a potenciais hídricos que permitam a ocorrência dos processos fisiológicos iniciais (fases I e II do processo de embebição), sem atingir umidade suficiente para que ocorra o elongamento celular e, conseqüentemente, a emergência da radícula (fase III) (HEYDECKER et al., 1975). Com esse tratamento, têm sido observados, em sementes de diversas espécies, ganhos significativos em porcentagem, velocidade e uniformidade de germinação. Bittencourt et

${ }_{1}^{1}$ Doutorando em Fisiologia Vegetal na Universidade Federal de Lavras/UFLA - Cx.P. 3037 - 37200-000 - Lavras/MG - Ibonome@hotmail.com

2 Professor Titular do Departamento de Agricultura na Universidade Federal de Lavras/UFLA - Cx.P. 3037 - 37200-000 - Lavras/MG.

${ }^{3}$ Aluno do Curso de Agronomia na Universidade Federal de Lavras/UFLA - Cx.P. 3037 - 37200-000 - Lavras/MG.

${ }^{4}$ Mestre em Fitotecnia pela Universidade Federal de Lavras/UFLA - Cx.P. 3037 - 37200-000 - Lavras/MG. 
al. (2004) verificaram incrementos na germinação e no vigor de sementes de aspargo de baixa qualidade fisiológica quando condicionadas em solução de PEG. Resultados semelhantes foram verificados por Giúdice et al. (1999) e Nunes et al. (2002), ambos em trabalhos com sementes de soja. O benefício do uso de sais contendo nitrato no controle osmótico de sementes é controverso. De acordo com Nerson \& Govers (1986), a utilização desses sais é mais eficiente que a de outros agentes osmóticos, pois, além de não reduzir a disponibilidade de oxigênio na solução, fato constatado quando se utiliza PEG (BUJALSKI \& NIEMOW, 1991), estes sais podem servir como potencial fonte de nitrogênio e outros nutrientes essenciais durante a germinação. No entanto, devido a seu baixo peso molecular estes podem penetrar nas sementes e causar toxidez às plântulas. Frett et al. (1991) observaram efeitos negativos sobre sementes de aspargos quando estas foram condicionadas em solução de $\mathrm{KNO}_{3}$.

Desta forma, objetivou-se com este trabalho, avaliar o efeito do pré-condicionamento osmótico sobre a qualidade fisiológica de sementes de Brachiaria brizantha.

\section{MATERIAL E MÉTODOS}

O presente trabalho foi conduzido no Laboratório de Análise e Biotecnologia de Sementes do Departamento de Agricultura da Universidade Federal de Lavras. As sementes de Brachiaria foram condicionadas em soluções de PEG 6000, $\mathrm{KNO}_{3}$ e PEG $6000+\mathrm{KNO}_{3}(1: 1)$ sob imersão com aeração, em concentrações capazes de desenvolver potenciais hídricos de $-0,9,-1,1$ e $-1,4 \mathrm{MPa}$, em quatro períodos de embebição (12, 24, 48 e 72 horas), totalizando 36 tratamentos, acrescidos de duas testemunhas (presença e ausência de escarificação em ácido sulfúrico por 15 minutos). A aeração foi realizada com a utilização de bombas habitualmente utilizadas em aquários. O preparo das soluções de PEG e $\mathrm{KNO}_{3}$ foi baseado nas equações propostas por Michel \& Kaufmann (1973) e Hillel (1971), respectivamente. A solução de PEG $6000+\mathrm{KNO}_{3}$, baseada nas mesmas equações, constou de mistura realizada na proporção de 1:1.

Após o condicionamento, as sementes de Brachiaria foram lavadas em água corrente por 5 minutos para eliminar resíduos da solução. Em seguida, foram secadas à temperatura ambiente até atingirem o teor de água inicial e avaliadas quanto à qualidade fisiológica por meio dos testes de germinação, índice de velocidade de protrusão radicular e $\mathrm{T}_{50}$ (tempo para ocorrência de 50\% de germinação).
Foi utilizado o delineamento inteiramente casualizado, em esquema fatorial $(3 \times 3 \times 4)+2$ (três solutos, três potenciais hídricos, quatro tempos de embebição), e duas testemunhas (ausência e presença de escarificação com ácido sulfúrico), com 4 repetições.

\subsection{Teste de germinação, índice de velocidade de protrusão radicular $\mathbf{e} \mathbf{T}_{\mathbf{5 0}}$}

Estes testes foram conduzidos com quatro repetições de 50 sementes. Cada repetição foi distribuída em caixas plásticas transparentes (tipo gerbox 11,5 x $11,5 \times 3,5 \mathrm{~cm}$ ) sobre duas folhas de papel mata-borrão, umedecidas com água em quantidade equivalente a 2,5 vezes o peso do papel não-hidratado. As sementes permaneceram a $25^{\circ} \mathrm{C}$ sob luz alternada $12 / 12 \mathrm{~h}$ (escuro/ luz) em câmaras de germinação. As avaliações foram realizadas diariamente, considerando germinadas as plântulas que apresentaram raiz primária com comprimento maior ou igual a $1 \mathrm{~mm}$. Após a estabilização do número de sementes germinadas, foi calculado o índice de velocidade de protrusão radicular pela equação proposta por Maguirre (1962). A porcentagem de germinação das sementes foi avaliada após 21 dias, segundo as prescrições das Regras para Análise de Sementes e o $\mathrm{T}_{50}$ (tempo para ocorrência de $50 \%$ de germinação) calculado pela equação proposta por Guimarães (2000).

\section{RESULTADOS E DISCUSSÃO}

\subsection{Germinação}

Na germinação das sementes de Brachiaria foi verificado efeito significativo para o fator potencial hídrico e para a interação período de condicionamento $\mathrm{x}$ soluto.

Pela Tabela 1, fica evidenciado que a redução no potencial osmótico da solução tendeu a incrementar a germinação das sementes. Este resultado corrobora os observados por Hardegree \& Emmerich (1992) que, trabalhando com quatro espécies de gramíneas, verificaram maiores porcentagens de germinação nos tratamentos submetidos a tensões osmóticas mais negativas. Porém, Borges et al. (1994) e Braccini et al. (1996) verificaram que reduções no potencial osmótico da solução corresponderam a reduções na germinação das sementes. Para Heydecker et al. (1975), estas discordâncias devemse ao fato de a relação ideal entre temperatura, potencial osmótico e período de condicionamento, ser variável segundo a espécie e a cultivar. 
Pela Figura 1, observa-se que os valores de germinação das sementes escarificadas e não escarificadas foram próximos um do outro, indicando provável ausência de dormência das sementes. Verifica-se ainda que os valores de germinação das sementes imersas por um período de 12 horas em soluções contendo os diferentes solutos, não diferiram entre si e apresentaram valores próximos aos observados nas testemunhas escarificada e não escarificada.

De maneira geral, observa-se que, à medida que o período de condicionamento das sementes é aumentado, ocorre redução na porcentagem de germinação. Para as sementes imersas em solução de PEG, essa redução foi de $80 \%$ no período de 12 horas para $70 \%$ no período de 24 horas de embebição, permanecendo constante após este período.
Para as sementes imersas em soluções de $\mathrm{KNO}_{3}$ e $\mathrm{PEG}+\mathrm{KNO}_{3}$ verifica-se que estas apresentaram germinações semelhantes às sementes imersas em solução de PEG nos períodos de 12 e 24 horas. No entanto, à medida que o período de embebição das sementes na solução foi aumentando a porcentagem de germinação das sementes foi reduzida. Vale ressaltar que esta redução foi maior em solução de $\mathrm{KNO}_{3}$ do que na mistura $\mathrm{PEG}+\mathrm{KNO}_{3}$. Provavelmente isto ocorreu em função do baixo peso molecular do sal utilizado, que pode ter penetrado nos tecidos das sementes causando fitotoxidez, que foi tão mais severa quanto maior o tempo de exposição das sementes à solução. Resultados semelhantes a este foram verificados por Haigh \& Barlow (1987) que, avaliando a eficiência do condicionamento fisiológico em sementes de Sorghum $s p$ em solução de $\mathrm{KNO}_{3}$, observaram efeito fitotóxico desta solução às sementes.

TABELA 1 - Resultados médios de germinação de sementes de Brachiaria brizantha osmocondicionadas em diferentes potenciais hídricos. UFLA, Lavras/MG, 2005.

\begin{tabular}{cc}
\hline Potencial Hídrico (MPa) & Germinação (\%) \\
\hline$-0,9$ & $64,54 \mathrm{~B}$ \\
$-1,1$ & $65,92 \mathrm{AB}$ \\
$-1,4$ & $68,92 \mathrm{~A}$ \\
\hline
\end{tabular}

Médias seguidas de uma mesma letra maiúscula na coluna não diferem entre si pelo teste de Tukey, a $5 \%$ de probabilidade.

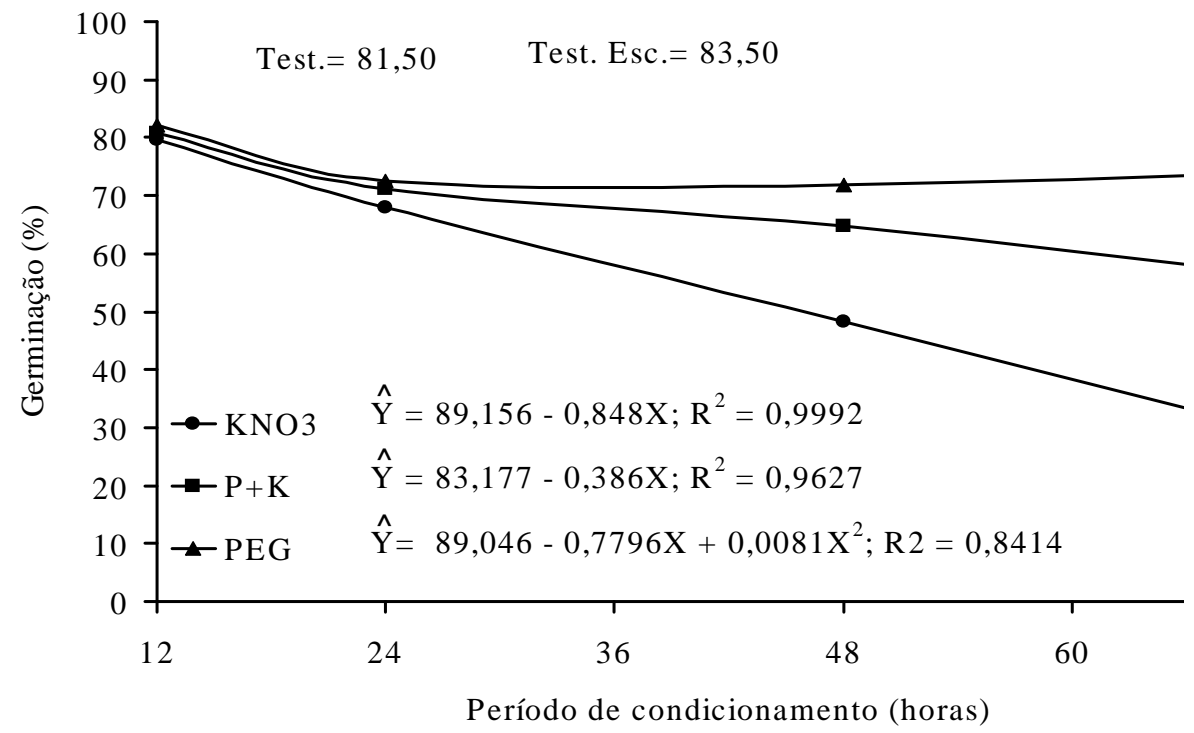

FIGURA 1 - Estimativa da porcentagem de germinação de sementes de Brachiaria brizantha em função do período de condicionamento (12, 24, 48 e 72 horas) e da solução de imersão ( $\mathrm{PEG}, \mathrm{KNO}_{3}$ e $\mathrm{PEG}+\mathrm{KNO}_{3}$ ) na temperatura de $25^{\circ} \mathrm{C}$. UFLA, Lavras/MG, 2005.

Ciênc. agrotec., Lavras, v. 30, n. 3, p. 422-428, maio,jun., 2006 


\section{2 Índice de velocidade de protrusão radicular}

Para o índice de velocidade de protrusão radicular, verificou-se efeito significativo para o fator potencial hídrico, para a interação período de condicionamento $\mathrm{x}$ soluto e entre testemunhas.

De maneira semelhante ao observado para a porcentagem de germinação, verifica-se, pela Tabela 2 , que a redução no potencial osmótico da solução tendeu a incrementar o índice de velocidade de protrusão radicular das sementes.

Para as testemunhas (Figura 2), observa-se uma maior velocidade de protrusão radicular quando as sementes foram escarificadas com ácido sulfúrico $(17,73)$ em comparação às sementes não escarificadas $(12,77)$, sugerindo que a escarificação química das sementes proporcionou uma maior rapidez em sua germinação.
Observa-se, ainda, pela Figura 2, que o osmocondicionamento de sementes de Brachiaria brizantha por um período de 12 horas de embebição foi o que proporcionou maior índice de velocidade de protrusão radicular para todas as soluções testadas. Vale ressaltar que, neste período de condicionamento, todos os tratamentos se sobressaíram em relação às sementes não escarificadas (testemunha). No entanto, nenhum superou as sementes escarificadas. Merecem destaque as sementes condicionadas em solução de $\mathrm{KNO}_{3}$ por um período de 12 horas que se sobressaíram em relação às submetidas aos demais tratamentos e sobre a testemunha sem escarificação. Para Khan et al. (1980/81), este aumento na velocidade de germinação de sementes condicionadas em solução contendo nitrato está relacionado com o aumento de substrato para aminoácidos e síntese de proteínas.

TABELA 2 - Resultados médios do índice de velocidade de protrusão radicular (IVPR) de sementes de Brachiaria brizantha osmocondicionadas em diferentes potenciais hídricos. UFLA, Lavras/MG, 2005.

\begin{tabular}{cc}
\hline Potencial Hídrico $(\mathrm{MPa})$ & IVPR \\
\hline$-0,9$ & $10,28 \mathrm{~B}$ \\
$-1,1$ & $10,62 \mathrm{AB}$ \\
$-1,4$ & $11,16 \mathrm{~A}$ \\
\hline
\end{tabular}

Médias seguidas de uma mesma letra maiúscula na coluna não diferem entre si pelo teste de Tukey, a 5\% de probabilidade.

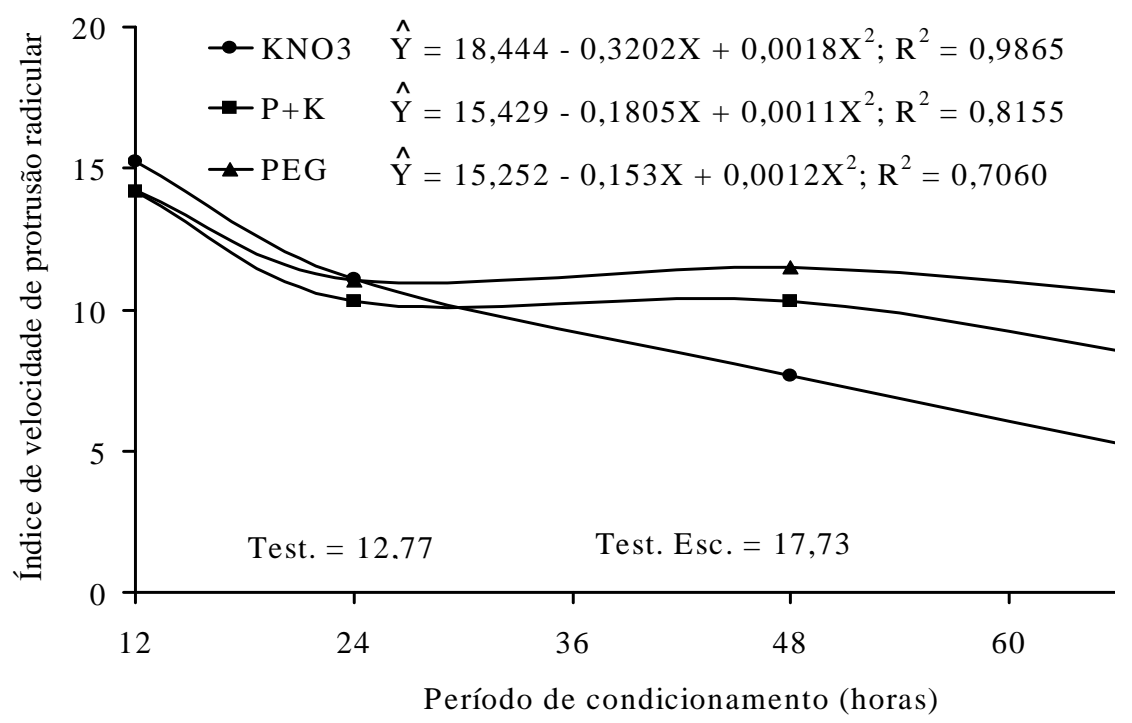

FIGURA 2 - Estimativa do índice de velocidade de protrusão radicular de sementes de Brachiaria brizantha em função do período de condicionamento (12, 24, 48 e 72 horas) e das soluçães de imersão ( $\mathrm{PEG}, \mathrm{KNO}_{3}$ e $\mathrm{PEG}+\mathrm{KNO}_{3}$ ). UFLA, Lavras/MG, 2005. 
Observa-se ainda, pela Figura 2, que de maneira geral, quando o período de condicionamento das sementes foi elevado de 12 para 24 horas, houve queda acentuada na velocidade de protrusão radicular em todos os tratamentos. Porém, quando esse período passou para 48 horas de embebição, verificou-se acréscimo na velocidade de protrusão radicular das sementes condicionadas em solução de PEG e PEG+KNO${ }_{3}$. A partir daí houve tendência de queda com o aumento do período de condicionamento.

Vale ressaltar que, nesta pesquisa, os valores de velocidade de protrusão radicular das sementes condicionadas em soluções de PEG e PEG+KNO $\mathrm{KN}_{3}$ foram próximos entre si, obedecendo a mesma tendência. No entanto, observa-se, de maneira geral, que as sementes condicionadas em solução de PEG se sobressaíram em relação às imersas em solução de $\mathrm{PEG}+\mathrm{KNO}_{3}$. Para as sementes condicionadas em solução de $\mathrm{KNO}_{3}$ verificouse maior desempenho quando estas foram embebidas por 12 horas. No entanto, a partir de 24 horas de embebição, a velocidade de protrusão radicular das sementes imersas nesta solução foi menor do que a ocorrida nos demais solutos utilizados, confirmando o provável efeito fitotóxico dessa solução sobre as sementes.

\subsection{Tempo médio para ocorrência de $50 \%$ de germinação}

Para o vigor das sementes, medido pelo $\mathrm{T}_{50}$, verificou-se significância nas interações período de condicionamento $\mathrm{x}$ soluto e período de condicionamento $\mathrm{x}$ potencial hídrico. Observou-se, ainda, significância entre testemunhas.

Para as testemunhas, verificou-se que a escarificação das sementes foi eficiente em reduzir o tempo $\left(\mathrm{T}_{50}\right)$ para 1,99 dia (dados não apresentados) em relação ao observado para as sementes não escarificadas 2,80 dias (dados não apresentados). Isto indica que a escarificação das sementes em ácido sulfúrico possibilita maior uniformidade na germinação das sementes em comparação às sementes sem escarificação.
Já para a interação período de condicionamento $\mathrm{x}$ soluto, foi observado que, em todas as soluções, o período de imersão de 12 horas foi o que proporcionou maior redução nas médias do tempo para que $50 \%$ das sementes emitissem a raiz primária (Tabela 3). Porém, esses valores não diferiram estatisticamente dos observados quando as sementes foram imersas em soluções de PEG e $\mathrm{PEG}+\mathrm{KNO}_{3}$ por um período de 48 horas de embebição. A emergência da raiz primária em um menor período de tempo parece ser a principal vantagem do condicionamento fisiológico, fato este comprovado por diversos autores (CAVALLARO et al., 1994; DELL'ÁQUILA \& TRITTO, 1991). Estes resultados também foram observados no teste de germinação e índice de velocidade de protrusão radicular (Figuras 1 e 2). Quando as sementes foram imersas por um período de 72 horas, os valores de $\mathrm{T}_{50}$ foram, de maneira geral, superiores; porém, observa-se que esses valores neste período de condicionamento não diferiram daqueles observados para o período de 24 horas.

Quanto ao soluto, verifica-se que no menor período de embebição (12 horas) a imersão das sementes em solução de $\mathrm{KNO}_{3}$ foi a que possibilitou maior redução no tempo para que $50 \%$ das sementes emitissem a raiz primária porém, à medida que o tempo de condicionamento foi aumentado, não foram observadas diferenças entre os valores (Tabela 3) Trabalhando com sementes de tomate condicionadas em soluções de $\mathrm{KNO}_{3}$ e PEG-8000, Alvarado \& Bradford (1988) observaram efeitos positivos dessas soluções em reduzir o tempo médio para $50 \%$ de germinação das sementes.

Pelos resultados da Tabela 4, verifica-se, maior desempenho das sementes quanto ao $\mathrm{T}_{50}$, quando estas foram condicionadas por um período de 12 horas, em relação às sementes submetidas aos outros períodos de condicionamento, independentemente da concentração do soluto utilizada, com exceção dos valores observados para as sementes condicionadas por um período de 48 horas na concentração de $-0,9 \mathrm{MPa}$, os quais não diferiram daqueles observados para as condicionadas por um período de 12 horas.

TABELA 3 - Valores médios do $\mathrm{T}_{50}$ (dias) de sementes de Brachiaria brizantha em função do período de condicionamento e do soluto. UFLA, Lavras/MG, 2005.

\begin{tabular}{cccc}
\hline $\begin{array}{c}\text { Período de Condicionamento } \\
\text { (horas) }\end{array}$ & \multicolumn{3}{c}{ Soluto } \\
\cline { 2 - 4 } & PEG & KNO $_{\mathbf{3}}$ & PEG+KNO $_{\mathbf{3}}$ \\
\hline 12 & $2,55 \mathrm{Ab}$ & $2,10 \mathrm{Aa}$ & $2,43 \mathrm{Ab}$ \\
24 & $3,17 \mathrm{Cb}$ & $2,73 \mathrm{Ba}$ & $3,13 \mathrm{Bb}$ \\
48 & $2,79 \mathrm{ABa}$ & $2,85 \mathrm{Ba}$ & $2,74 \mathrm{Aa}$ \\
72 & $2,99 \mathrm{BCa}$ & $2,88 \mathrm{Ba}$ & $3,15 \mathrm{Ba}$ \\
\hline
\end{tabular}

Médias seguidas de uma mesma letra minúscula na linha e maiúscula na coluna não diferem entre si pelo teste de Tukey, a $5 \%$ de probabilidade.

Ciênc. agrotec., Lavras, v. 30, n. 3, p. 422-428, maio,jun., 2006 
TABELA 4 - Valores médios do $\mathrm{T}_{50}$ (dias) de sementes de Brachiaria brizantha em função do período de condicionamento e do potencial hídrico. UFLA, Lavras/MG, 2005.

\begin{tabular}{cccc}
\hline \multirow{2}{*}{$\begin{array}{c}\text { Período de Condicionamento } \\
\text { (horas) }\end{array}$} & \multicolumn{3}{c}{ Potencial hídrico (MPa) } \\
\cline { 2 - 4 } & $\mathbf{- 0 , 9}$ & $\mathbf{- 1 , 1}$ & $\mathbf{- 1 , 4}$ \\
\hline 12 & $2,39 \mathrm{Aa}$ & $2,31 \mathrm{Aa}$ & $2,39 \mathrm{Aa}$ \\
24 & $3,09 \mathrm{Ba}$ & $2,96 \mathrm{Ba}$ & $2,98 \mathrm{Ba}$ \\
48 & $2,71 \mathrm{Aa}$ & $2,85 \mathrm{Ba}$ & $2,82 \mathrm{Ba}$ \\
72 & $3,31 \mathrm{Bb}$ & $2,89 \mathrm{Ba}$ & $2,81 \mathrm{Ba}$ \\
\hline
\end{tabular}

Médias seguidas de uma mesma letra minúscula na linha e maiúscula na coluna não diferem entre si pelo teste de Tukey, a $5 \%$ de probabilidade.

Em relação à concentração do soluto não foi verificada diferença significativa entre os tempos para que $50 \%$ das sementes germinassem, com exceção da observada para sementes condicionadas por um período de 72 horas a uma concentração de $-0,9 \mathrm{MPa}$, para as quais foi requerido um tempo maior para que $50 \%$ da germinação fossem alcançados.

\section{CONCLUSÕES}

O condicionamento osmótico de sementes de Brachiaria brizantha em soluções aeradas de PEG-6000, $\mathrm{KNO}_{3}$ e da mistura PEG $6000+\mathrm{KNO}_{3}$ por um período de 12 horas, promoveu incremento na velocidade de protrusão radicular em relação à testemunha não escarificada.

Sementes osmocondicionadas em solução de $\mathrm{KNO}_{3}$ por um período de 12 horas, apresentaram uniformidade de germinação superior à testemunha não escarificada e à das sementes imersas nas demais soluções.

\section{REFERÊNCIAS BIBLIOGRÁFICAS}

ALVARADO, A. D.; BRADFORD, K. J. Priming and storage of tomato (Lycopersicon esculentum Mill.) seeds: I. effects of storage temperature on germination rate and viability. Seed Science and Technology, Zürich, v. 16, n. 3, p. 601-612, 1988.

BITTENCOURT, M. L. C.; DIAS, D. C. F. dos S.; DIAS, L. A. dos S.; ARAÚJO, E. F. Efeito do condicionamento osmótico das sementes na germinação e no crescimento das plântulas de aspargo. Revista Brasileira de Sementes, Brasília, v. 26, n. 1, p. 50-56, 2004.

BORGES, E. E. L.; SILVA, L. F.; BORGES, R. C. G. Avaliação do osmocondicionamento na germinação de sementes de quaresminha (Miconia candolleana Trian). Revista Brasileira de Sementes, Brasília, v. 16, n. 1, p. 90-94, 1994.
BRACCINI, A. de L.; RUIZ, H. A.; BRACCINI, M. C. L.; REIS, M. S. Germinação e vigor de sementes de soja sob estresse hídrico induzido por soluções de cloreto de sódio, manitol e polietileno glicol. Revista Brasileira de Sementes, Brasília, v. 18, n. 1, p. 10-16, 1996.

BUJALSKI, W.; NIEMOW, A. W. Large-scale osmotic priming of onion seeds: a comparison of different strategies for oxygenation. Scientia Horticulturae, Amsterdam, v. 46, n. 1, p. 13-24, 1991.

CASTRO, C. R. T.; CARVALHO, W. L.; REIS, F. P. Influência do tratamento com ácido sulfúrico na germinação de sementes de Brachiaria brizantha Stapf. Revista Ceres, Lavras, v. 41, n. 236, p. 451-458, 1996.

CAVALLARO, V.; MAUROMICALE, G.; VINCENZO, G. D.; DIVICENZO, G.; QUAGLIOTTI, B. P. Effects of osmoconditioning on emergence characteristics of the tomato (Lycopersicum esculentum Mill.). Acta Horticulturae, Amsterdam, v. 362, p. 213-220, 1994.

DELL'ÁQUILA, A.; TRITTO, V. Germination and biochemical activities in wheat seeds following delayed harvesting, ageing and osmotic priming. Seed Science and Technology, Zurich, v. 19, n. 1, p. 73-82, 1991.

FRETT, J. J.; PILL, W. G.; MORNEAU, D. C. A comparison of priming agents for tomato and asparagus seeds. HortScience, Alexandria, v. 26, n. 9, p. 1158-1158, 1991.

GIÚDICE, M. P. del et al. Efeito do condicionamento osmótico na germinação de sementes de dois cultivares de soja. Revista Ceres, Lavras, v. 46, n. 266, p. 435-444, 1999. 
GUIMARÃES, R. M. Tolerância à dessecação e condicionamento fisiológico em sementes de cafeeiro (Coffea arabica L.). 2000. 180 p. Tese (Doutorado em Fitotecnia) - Universidade Federal de Lavras, Lavras, 2000.

HAIGH, A. M.; BARLOW, E. W. R. Germination and priming of tomato, carrot, onion, and sorghum seeds in a range of osmotic. Journal of the American Society Horticultural Science, Alexandria, v. 112, n. 2, p. 202208, Mar. 1987.

HARDEGREE, S. P.; EMMERICH, W. E. Effect of polyethylene glycol exclusion on the water potential of solution-saturated filter paper. Plant Physiology, Rockville, v. 92, n. 2, p. 462-466, Feb. 1992.

HEYDECKER, W.; HIGGINS, J.; TURNER, Y. J. Invigoration of seeds. Seed Science and Technology, Zurich, v. 3, n. 3/4, p. $881-888,1975$.

HILLEL, D. Soil and water: physical principles and processes. New York: Academic, 1971. 288 p.
KHAN, A. A.; PECK, N. H.; SAMIMY, C. Seed osmoconditioning: physiological and biochemical changes. Israel Journal of Botany, Jerusalem, v. 29, n. 1/4, p. 133$144,1980 / 81$.

MAGUIRRE, J. D. Speed of germination: aid seedling emergence and vigor. Crop Science, Madison, v. 2, n. 2, p. 176-177, Mar./Apr. 1962.

MICHEL, B. E.; KAUFMANN, M. R. The osmotic potencial of poliethylene glycol 6000. Plant Physiology, Rockville, v. 51, n. 5, p. 914-916, May 1973.

NERSON, H.; GOVERS, A. Salt priming of muskmelon seeds for low-temperature germination. Scientia Horticulturae, Amsterdam, v. 28, p. 85-91, 1986.

NUNES, U. R.; SILVA, A. A.; REIS, M. S.; SEDIYAMA, C. S.; SEDIYAMA, T. Efeito do condicionamento osmótico de sementes de soja sobre a habilidade competitiva da cultura com as plantas daninhas. Planta Daninha, Viçosa, v. 20, n. 1, p. 27-35, 2002. 